\title{
ЭФФЕКТИВНОСТЬ РЕАЛИЗАЦИИ ГОСУДАРСТВЕННОЙ ПРОГРАММЫ «УПРАВЛЕНИЕ ФЕДЕРАЛЬНЫМ ИМУЩЕСТВОМ» ЗА 2013-2020 ГОДЫ
}

\author{
(c) 2021 Звягинцев Петр Семенович \\ кандидат экономических наук, ведущий научный сотрудник \\ Институт экономики Российской академии наук, Россия, Москва \\ E-mail:petrz@bk.ru
}

В настоящей статье дан анализ эффективности реализации госпрограммы РФ «Управление федеральным имуществом»: количества пакетов акций по доле РФ в уставных капиталах акционерных обществ в 2013-2020 годах, объема поступлений, значений средств от продажи акций и иных форм участия в капитале, находящихся в федеральной собственности за период 2013-2020 гг., поступления доходов в федеральный бюджет, администрируемых Росимуществом в 2013-2020 гг.

Обосновывается вывод о приостановке приватизации эффективных государственных предприятий.

Ключевые слова: госпрограмма, управление, эффективность, федеральное имущество, акции, прибыль, дивиденды, приватизация, государственная и частная собственности.

Целью госпрограммы «Управление федеральным имуществом», утвержденной в 2014 году, было «Создание условий для эффективного управления федеральным имуществом, необходимым для выполнения государственных функций органами государственной власти Российской Федерации*.

Впоследствии, цель была заменена на «Совершенствование механизмов управления и приватизации федерального имущества»***.

Посредством госпрограммы в 2013-2020 годы правительство сокращало федеральное имущество с помощью приватизации.

Так, распределение количества пакетов акций по доле РФ в уставных капиталах акционерных обществ (АО) с долей 100\% в 2013 году было 1256 ед., а в 2020 году их осталось только 341 ед., то есть уменьшилось в 3,68 раз (рис. 1).

Аналогичная ситуация и с остальными АО с долей в уставных капиталах: 50-100\% соответственно 100 ед., 41 ед. и 2,44 раза, 25-50\% 223 ед., 66 ед. и 3,44 раза, менее 25\% 754 ед., 477 ед. и 1,58 раз. В целом сокращение долей в уставных капиталах акционерных обществ составило 2,33 раз.

На участие в управлении АО РФ принадлежит специальное право («Золотая акция»). Если в 2014 году их было 90, то в 2020 году -54 .
На начало 2020 года общее количество ФГУП по данным информационной системы отраслевых структурных подразделений ФГИАС ЕСУГИ составило 626 единиц, что меньше в 2,1 раза по сравнению с 2016 годом [1].

Все сокращения госпрограммы, перечисленные выше, реализовывались, в основном, путем проведения приватизации.

На рисунке 2 приведены средства от продажи акций и иных форм участия в капитале, находящихся в федеральной собственности за 20122020 гг. Финансовые средства от приватизации поступали неравномерно с 2013 по 2017 год. Если 2013 году фактические поступления от приватизации составили 41,7 млрд. руб., то в 2014 году 29,7 млрд. руб., а в 2015 году только 6,3 млрд. руб.

Наибольший объем денежных средств от приватизации поступило в 2016 году - 406,8 млрд. руб., что в 9,75 раз больше чем по сравнению с 2013 годом. И в 54,53 раза больше по сравнению с 2015 годом. Это произошло за счет продажи крупных корпораций: ПАО «НК «Роснефть», АК «АЛРОСА» (ПАО), ПАО АНК «Башнефть».

В целом (2013-2020 гг.) план по приватизации выполнен на 98,0\%.

Несмотря на ежегодные сокращения с 2013 по 2016 годы, федерального имущества фактические выплаты в бюджет по основным дохо-

\footnotetext{
" Постановление Правительства РФ от 15 апреля 2014 г. № 327 «Об утверждении государственной программы Российской Федерации «Управление федеральным имуществом».

" Постановление Правительства РФ от 31 марта 2017 г. № 381-12 «О внесении изменений в государственную программу Российской Федерации «Управление федеральным имуществом».
} 


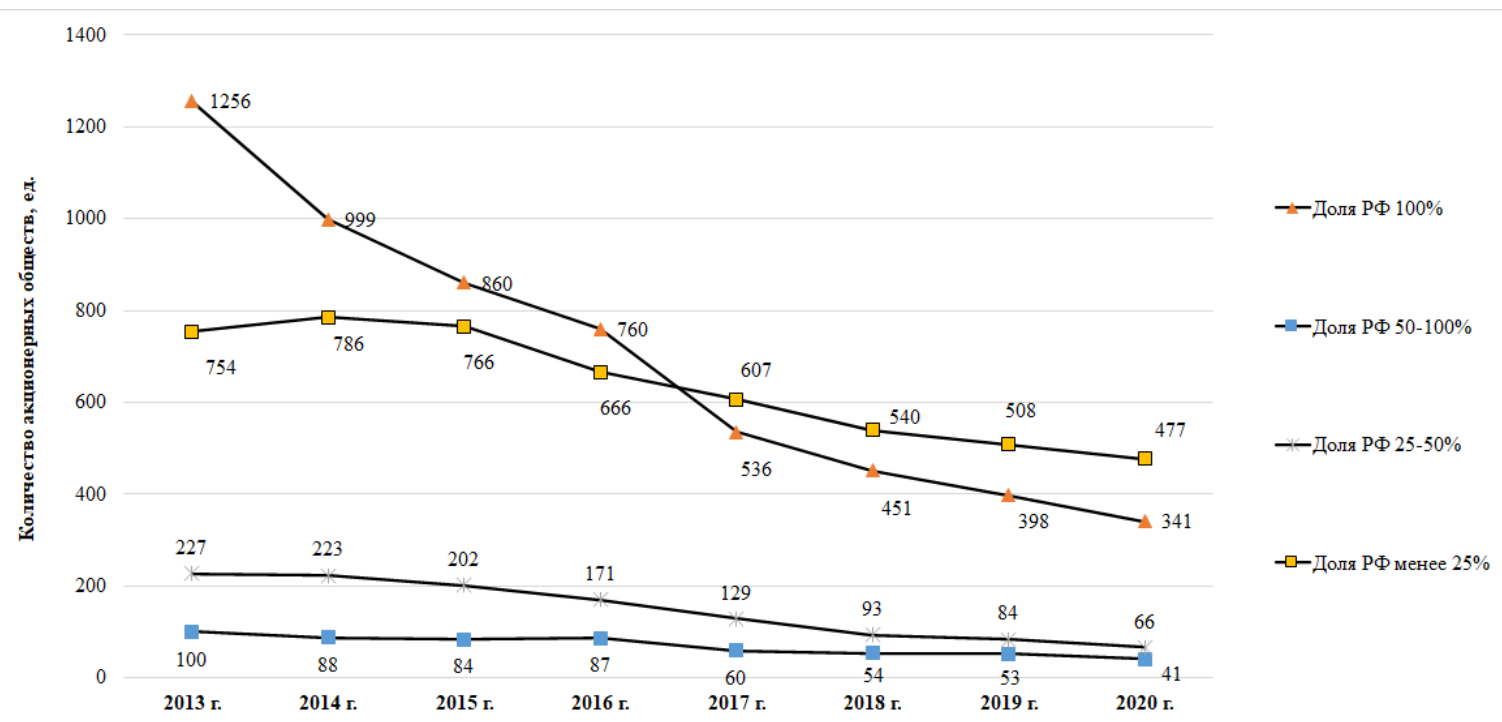

Puc. 1. Количество пакетов акций по доле РФ в уставных капиталах АО в 2013-2020 гг. [2]

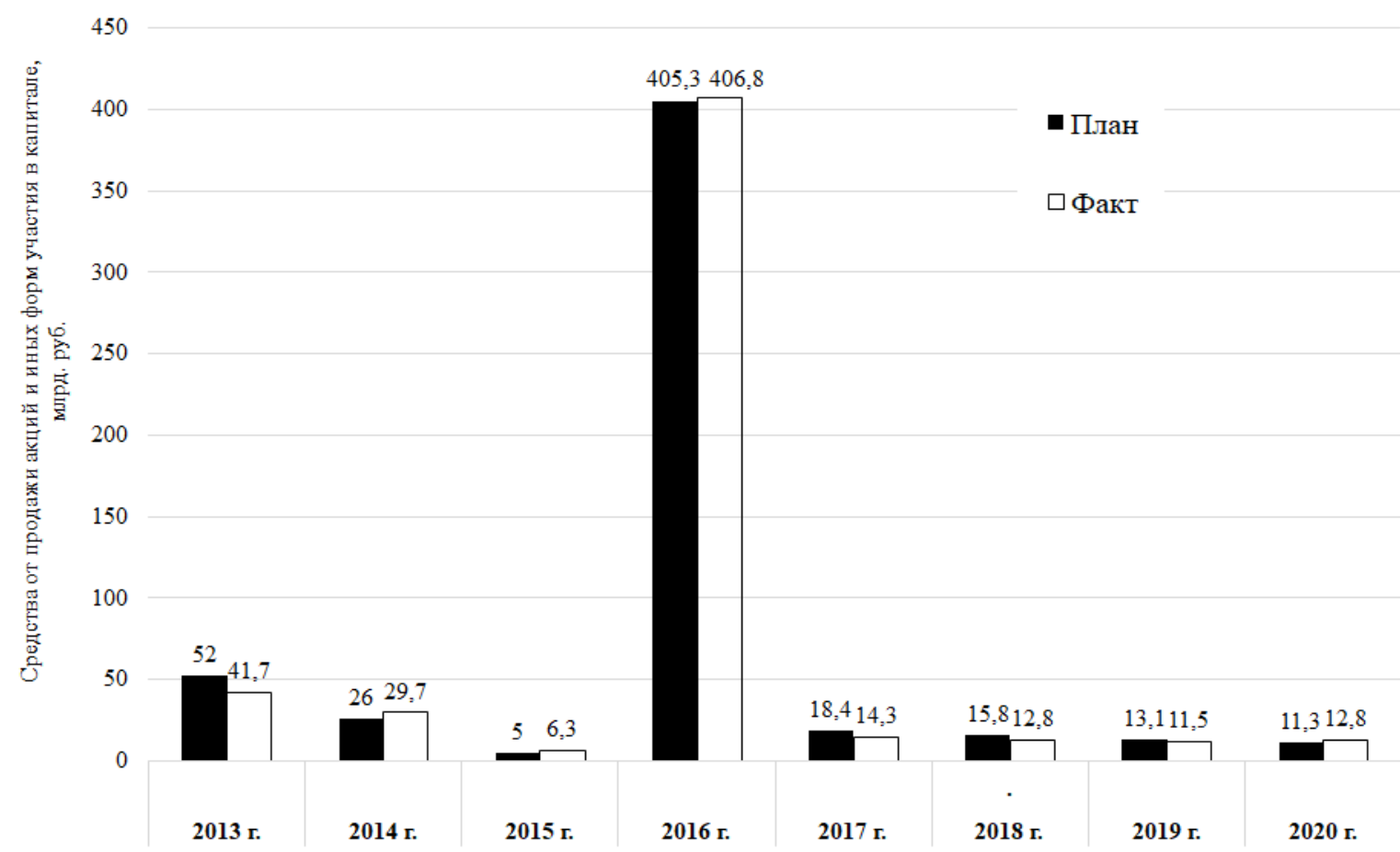

Puc. 2. Объем фактических поступлений и плановых значений средств от продажи акций и иных форм участия в капитале, находящихся в федеральной собственности за период 2013-2020 гг., млрд. руб. [1,8]

дам федерального бюджета, администрируемых Росимуществом, имеют тенденцию увеличения (см. рис. 3).

Так в федеральный бюджет доходов поступило 145,84 млрд. руб. в 2013 году, а в 2020 году 454,52 млрд. руб., т.е. доходы увеличились в 3,12 раза.

С 2013 по 2020 год поступление доходов в федеральный бюджет осуществляется не равномерно. В 2013 году поступления доходов в фе- деральный бюджет составили 145,84 млрд. руб., в 2014 году - 231,58 млрд. руб. и в 2016 году 941,81 млрд. руб.

Начиная с 2017 года и по 2019 год поступления в федеральный бюджет увеличиваются.

Доходы в виде прибыли, получаемые на доли в уставных (складочных) капиталах хозяйственных товариществ и обществ, или дивидендов по акциям, принадлежащим РФ в 2020 году составили 422,67 млрд. руб. По сравнению с 2013 го- 


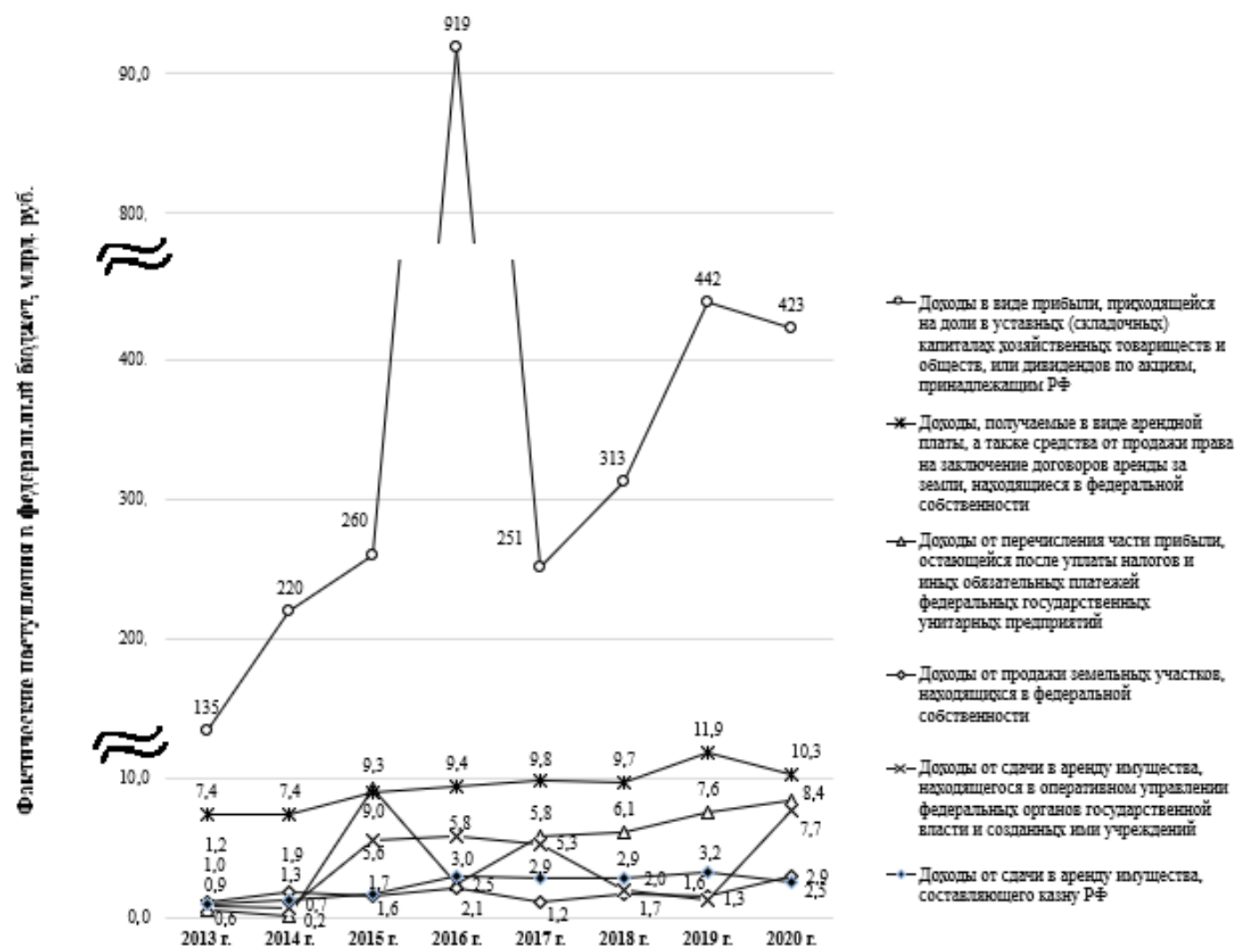

Puc. 3. Поступления основных доходов в федеральный бюджет в 2013-2020 гг., (ведомых Росимуществом), млн. руб. [4, 3, 5]

дом они увеличились в 3,14 раза.

В 2020 году доходы от перечисления части прибыли, остающейся после уплаты налогов, и иных обязательных платежей федеральных государственных унитарных предприятий равны 8,40 млрд. руб., и увеличились по сравнению 2013 годом в 14,48 раз. В 2020 году доходы от сдачи в аренду имущества, находящегося в оперативном управлении федеральных органов государственной власти были получены в сумме 7,66 млрд. руб., и увеличились в 8,61 раза по сравнению с 2013 годом.

Следовательно, несмотря на ежегодные сокращения имущества, ее приватизация, поступления федеральный бюджет доходов значительно возросли.

Вместе с тем, анализ финансово-экономической деятельности акционерных обществ с государственным участием показывает, что доля прибыльных обществ ежегодно не увеличивается, a, наоборот, уменьшается. Так доля прибыльных акционерных обществ с государственным участием составляла 68,4\% в 2016 году, в 2017 году $-66,8 \%$, и 66,1\% в 2018 году [4]. При том, что количество АО с госучастием в 2016 году было 1356 ед., а в 2018 году - 1084 ед., сокращение за этот период составляет 20,0\%.

Аналогичная ситуация и с ФГУП. Их доля прибыльных в 2015 году составляла 74,2\%, а в 2018 году - 68,9\%. Количество ФГУПов в 2016 году было 1293 ед., а в 2018 году - 821 ед.

Исходя из цели госпрограммы доля прибыльных АО с государственным участием и ФГУП по мере оптимизации их состава, структуры и сокращения (приватизации) должна увеличиваться, а не сокращаться. Или приватизируют только прибыльные ФГУПы и акционерные общества с государственным участием?

Сокращение количества ФГУП наряду с приватизацией, осуществляется также и путем преобразования предприятий в бюджетные учреждения. Реорганизация также осуществляется путем присоединения к иным ФГУП. В 20172019 годах сокращение ФГУП достигалось за счет приватизации (18,3\%), путем объединения предприятий $(28,9 \%)$, прекращения деятельности в силу банкротства $(32,6 \%)$ и преобразование в бюджетные и казенные учреждения $(13,0 \%)$ [4]. 
Реализация госпрограммы выявила массу недостатков:

1. Невозможно установить прямую взаимосвязь финансового обеспечения госпрограммы с результатами достижения большинства индикаторов, что говорит о низкой эффективности программы как инструмента бюджетного планирования. Нет четких целей и критериев оценки эффективности деятельности государственных организаций [8].

2. Несовершенна система корпоративного управления организациями с государственным участием.

3. Отсутствие достоверной информации о количестве акционерных обществ и ФГУП, подконтрольных государству и полноценной информации о результатах финансовой деятельности организаций с государственным участием. Сводная информация, представленная ФОИВ, ФГИАС ЕСУГИ не соответствует данным официальной статистики.

4. Формальный подход к формированию Прогнозного плана приватизации, недостаточный уровень координации участников приватизационных процедур и информационного обеспечения не способствуют исполнению плана.

5. Низкое качество реализуемых активов, ненадлежащая предпродажная подготовка, в том числе осуществленная без учета инвестиционной привлекательности.

6. Отсутствие заинтересованности региональных и муниципальных властей в приватизации государственной и муниципальной собственности.

7. Создание неудовлетворительного финансового состояния ФГУП в результате изъятия объектов, составляющие основной имущественный комплекс.

Реализация госпрограммы в 2013-2020 годы. Росимущество так и не смогло наладить учет: сколько всего акционерных обществ с государственным участием и сколько ФГУПов. Так в РФИ содержатся сведения об акциях 979 обществ на начало 2020 года. Однако Росимущество не имеет сведения о результатах финансовохозяйственной деятельности $606 \mathrm{AO}$, что составляет 61,9\% [4]. Противоречивость официальной информации о количестве АО с государственным участием и ФГУП достигает $20 \%$.

В отношении полноты сведений о деятельности ФГУП, имеются сведения о финансовых данных за 2017 год только по 398 предприятиям, что составляет 77\% от 514 подведомственных
ФГУП, а за 2018 год соответственно по 360 предприятиям из 490 (74\%) [4].

Отсутствие достоверной информации о результатах финансово-хозяйственной деятельности АО с государственным участием способствует принятию необоснованных управленческих решений в области корпоративного управления.

Независимо от наличия многих недостатков в деятельности АО с государственным участием и ФГУП, как мы отмечали выше, доля прибыльных АО с государственным участием и ФГУПов составляет более $50 \%$, но с каждым годом уменьшается. Так в 2019 году в федеральный бюджет АО с государственным участием перечислили доходов в виде дивидендов по акциям 441,6 млрд. руб. Доход от продажи акций и иных форм участия в капитале, находящихся в федеральной собственности средств в 2019 году составил только 13,1 млрд. руб., что в 33,71 раз меньше поступления в федеральный бюджет от доходов в виде дивидендов по акциям. Так надо ли приватизировать оставшиеся акционерные общества с государственным участием, приносящие государству доходы?

Необходимо отметить, что в бюджет государства поступают хоть какие-то дивиденды от акционерных обществ с государственным участием, а от приватизированных предприятий пополнения бюджета ждать не стоит. Частные предприятия не всегда платят налоги, так как могут найти способ отражать убытки. Приватизированные АО могут перепродаваться иностранным лицам и переносить свои головные компании за границу, регистрироваться в офшорах.

Однако Правительство РФ вместо устранения недостатков в работе АО с государственным участием и ФГУПов, планирует приватизировать дальше прибыльные предприятия, которые даже осуществляют деятельность в стратегических отраслях промышленности. Так, согласно плану, предусмотрена приватизация 86 ФГУП, приватизация доли участия РФ в 13 обществах с ограниченной ответственностью, 186 акционерных обществ на 2020-2022 годы [6].

Российские власти до сих пор руководствуются мифом о неэффективности госсектора. Поэтому они принимают решения о дальнейшей его приватизации. Они считают, что госсектор везде и всегда хуже частного.

Однако в условиях современной капиталистической системы крупными частными предприятиями руководит не частник предприятия, а совет директоров, который он нанимает. Госу- 
дарственными предприятиями также руководит совет директоров. На государственных предприятиях многое зависит от квалификации совета директоров и руководителя предприятия, мониторинга, контроля, конкуренции и другие.

По мнению известного экономиста Михаила Хазина «с точки зрения управления существует легенда, что частные предприятия работают более эффективно, чем государственные. Это враньё. Если у Вас есть система контроля, то государственные предприятия работают совершенно одинаково. С точки зрения менеджмента, какая разница, кто акционер [9].

В зарубежной практике есть много примеров эффективного управления государственными предприятиями [110].

Поэтому однозначно нельзя утверждать, что частный собственник эффективнее государства.

При управлении государственной собственностью используют разные инструменты. Наряду с приватизацией используется такой инструмент как национализация. Во многих капиталистических странах приняты законы о национализации. При различных экономических ситуациях используется как приватизация, так и национализация.

Государство, используя приватизацию и национализацию как инструмент государственной политики должно видеть всю перспективу развития тех или иных отраслей и понимать, как приватизация повлияет на их эффективность, или, может быть, придётся их национализировать.

Поэтому для эффективного развития государственных организаций необходимо повышение эффективности государственного управления государственными корпорациями и акционерными обществами с государственным участием. В условиях пандемии и экономических санкций значительная роль должна сохраняться за государственными предприятиями. Приватизация эффективных предприятий должна быть приостановлена.

\section{Библиографический список}

1. Годовой отчет о деятельности Росимущества за 2016 г. по реализации государственной программы «Управление федеральным имуществом», утвержденной постановлением Правительства Российской Федерации от 15 апреля 2014 г. № 327. file://C:/Users/komp/Downloads/Tekstovoe\%20opisanie\%20realizacii\% 20podprogrammy\%20(13).pdf

2. Заключение Счетной палаты Российской Федерации о результатах внешней проверки исполнения Федерального закона «О федеральном бюджете на 2019 год и на плановый период 2020 и 2021 годов» и бюджетной отчетности об исполнении федерального бюджета за 2019 год в Федеральном агентстве по управлению государственным имуществом (Руководитель - В.В.Яковенко) https://ach.gov.ru/upload/pdf/budget/POCИМУЩЕСТВО.pdf

3. Звягинцев П.С. Государственная программа Российской Федерации «Управление федеральным имуществом», как инструмент регулирования государственного сектора. // Вестник института экономики РАН. 2017. № 6. С. 61-73.

4. Отчет о результатах экспертно-аналитического мероприятия «Анализ практики формирования и реализации в 2017-2018 годах и истекшем периоде 2019 года дивидендной политики при осуществлении от имени Российской Федерации прав акционера (участника) хозяйственных обществ, акции (доли) в уставных (складочных) капиталах которых находятся в федеральной собственности, и полномочий собственника имущества федеральных государственных унитарных предприятий при определении направлений распределения прибыли, остающейся после уплаты налогов и иных обязательных платежей федеральных государственных унитарных предприятий». ach.gov.ru>upload/iblock/24d/...pdf

5. Показатели, характеризующие эффективность управления государственным имуществом. https://roskazna. gov.ru/ispolnenie-byudzhetov/pokazateli-kharakterizuyushchie-effektivnost-upravleniya-gosudarstvennymimushchestvom/

6. Распоряжение Правительства РФ от 31 декабря 2019 г. о 3260-р «Прогнозный план (программа) приватизации федерального имущества и основные направления приватизации федерального имущества на 2020-2022 годы». https://www.rosim.ru/documents/367399

7. Счетная палата отметила среднюю эффективность управления госимуществом в 2019 году. tass.ru>Экономика и бизнес 9530735

8. Управление федеральным имуществом. Бюллетень Счетной палаты РФ № 5 (282) 2021 г. Бюллетень СП № 5. pdf

9. Хазин Михаил. Радиостанция комсомольская правда, слушать Мардана онлайн 8 ноября 2021 года.

10. Эффективное управление государственной собственностью в 2018-2024 гг. и до 2035 г. // Аналитический доклад / ЦСР. - 2018. 